\title{
Jindřich Nečas
}

Application of Rothe's method to abstract parabolic equations

Czechoslovak Mathematical Journal, Vol. 24 (1974), No. 3, 496-500

Persistent URL: http://dml.cz/dmlcz/101263

\section{Terms of use:}

(C) Institute of Mathematics AS CR, 1974

Institute of Mathematics of the Czech Academy of Sciences provides access to digitized documents strictly for personal use. Each copy of any part of this document must contain these Terms of use.

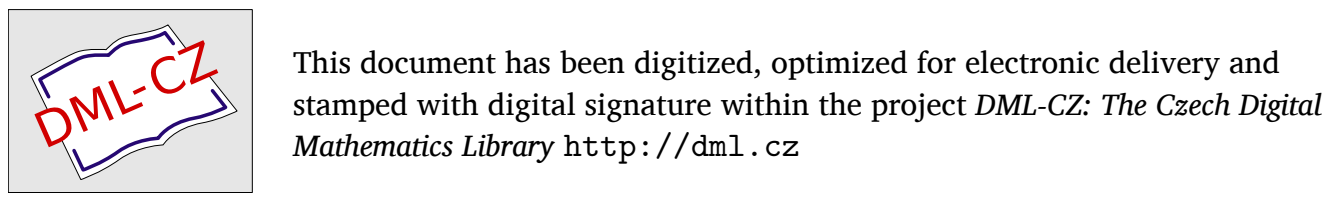




\title{
APPLICATION OF ROTHE'S METHOD TO ABSTRACT PARABOLIC EQUATIONS
}

\author{
JINDŘICH NEČAS, Praha
}

(Received August 25, 1973)

Introduction. The method of Rothe, introduced by Rothe in his paper [1], for the investigation of parabolic equations, was used by many authors, see for example O. A. Ladyženskaja [2], A. M. Ilujin, A. S. Kalašnikov, O. A. Olejnik [3]. Recently, a paper of K. REKTORYS [4] and papers of J. KAČUR [5] led the author to apply this method on the initial value problem for abstract parabolic equations $\mathrm{du} / \mathrm{d} t+A(u(t))=f(t)$ with $A$ a nonlinear operator. The author followed the paper of F. E. BROWDER [6], where the theory of semigroups is used and generalised his result for nonvanishing $f(t)$; see also H. BRÉzIs [7]. The method of Rothe consists in replacing the equation in fixed points $t_{j}=j h$, by $\left(u\left(t_{j}\right)-u\left(t_{j-1}\right)\right) / h+A\left(u\left(t_{j}\right)\right)=$ $=f\left(t_{j}\right)$. The nonlinear operator $A$ is supposed monotone in its domain $D(A) \subset H$, where $H$ is a real Hilbert space, and such that Range $(A+I)=H$. If $u_{0} \in D(A)$ and if $f$ is a continuous function from the interval $\langle 0, T\rangle$ to $H$ and of bounded variation, then a unique solution of the problem exists in the sense precised below and the piecewise linear functions or piecewise constant functions inset in points $t_{j}$ tend uniformly in the interval $\langle 0, T\rangle$ for $h \rightarrow 0$ to the solution.

Assertions and main theorem. Let the operator $A$ be monotone in $D(A)$ :

$$
(A u-A v, u-v) \geqq 0 \forall u, v \in D(A)
$$

and let us suppose that

$$
(A+I)(D(A))=H .
$$

Let $u_{0}$ be in $D(A)$ and $f$ in $C(\langle 0, T\rangle, H)$ with bounded variation in the interval $\langle 0, T\rangle$. By a solution of the problem

$$
\frac{\mathrm{d} u}{\mathrm{~d} t}+A(u(t))=f(t), \quad 0 \leqq t \leqq T, \quad u(0)=u_{0},
$$

we mean a strongly continuous function $u:\langle 0, T\rangle \rightarrow H$, weakly differentiable to $H$ for $t \in\langle 0, T\rangle$, such that $u(t) \in D(A)$ for $t \in\langle 0, T\rangle, A(u(t))$ is weakly continuous, 
$u(t)$ satisfies the equation (3) for $t \in\langle 0, T\rangle$ and the initial condition in the obvious sens. (See [6].)

Put for $\lambda>0: A_{\lambda}=A+\lambda I$. We obtain as in [6]:

Assertion 1. For $\lambda>0$, Range $\left(A_{\lambda}\right)=H$ and $\left\|A_{\lambda}^{-1} x-A_{\lambda}^{-1} y\right\| \leqq \lambda^{-1}\|x-y\|$.

Proof. Let $u, v \in D(A)$. Then $\left(A_{\lambda} u-A_{\lambda} v, u-v\right) \geqq \lambda\|u-v\|^{2}$, hence $\|u-v\| \leqq$ $\leqq \lambda^{-1}\left\|A_{\lambda} u-A_{\lambda} v\right\|$. If for some $\lambda_{0}>0$ the Range $\left(A_{\lambda_{0}}\right)=H$, then $A_{\lambda_{0}}^{-1}$ is defined and is Lipschitzian with Lipschitz constant $\lambda_{0}^{-1}$. To solve the equation $A_{\lambda} u=y$, put $u=A_{\lambda_{0}}^{-1} x$. We obtain the equation

$$
x+\left(\lambda-\lambda_{0}\right) A_{\lambda_{0}}^{-1} x=y,
$$

whose solution gives a solution of the original equation. If $\left|\lambda-\lambda_{0}\right| \lambda_{0}^{-1}<1$, then by the theorem on contractive mappings, the equation (4) has a unique solution, q.e.d.

Let $h=T / n, t_{j}=j h, j=0,1, \ldots, n$ and put $z_{0}=u_{0}, A z_{1}+\left(z_{1}-z_{0}\right) / h=$ $=f\left(t_{1}\right), A\left(z_{j}\right)+\left(z_{j}-z_{j-1}\right) / h=f\left(t_{j}\right), j=1,2, \ldots, n$. It follows from the Assertion 1 that $z_{j}$ are uniquely determined. We have

$$
\left(A z_{1}-A z_{0}, z_{1}-z_{0}\right)+\frac{\left\|z_{1}-z_{0}\right\|^{2}}{h}=\left(f\left(t_{1}\right), z_{1}-z_{0}\right)-\left(A z_{0}, z_{1}-z_{0}\right),
$$

hence

$$
h^{-1}\left\|z_{1}-z_{0}\right\| \leqq\left\|f\left(t_{1}\right)\right\|+\left\|A z_{0}\right\|
$$

and similarly for $j \geqq 2:\left(A z_{j}-A z_{j-1}, z_{j}-z_{j-1}\right)+\left\|z_{j}-z_{j-1}\right\|^{2} / h=\left(f\left(t_{j}\right)\right.$, $\left.z_{j}-z_{j-1}\right)-\left(f\left(t_{j-1}\right), z_{j}-z_{j-1}\right)+h^{-1}\left(z_{j-1}-z_{j-2}, z_{j}-z_{j-1}\right)$, so

$$
h^{-1}\left\|z_{j}-z_{j-1}\right\| \leqq\left\|f\left(t_{j}\right)-f\left(t_{j-1}\right)\right\|+h^{-1}\left\|z_{j-1}-z_{j-2}\right\| .
$$

We obtain from (5) and (6)

$$
h^{-1}\left\|z_{j}-z_{j-1}\right\| \leqq \underset{\langle 0, T\rangle}{\operatorname{Var} f}+\underset{\langle 0, T\rangle}{\operatorname{Max}}\|f(t)\|+\left\|A z_{0}\right\| .
$$

Put in $[0, T], z^{n}(t)=z_{j-1}+h^{-1}\left(t-t_{j-1}\right)\left(z_{j}-z_{j-1}\right)=h^{-1}\left(h-\left(t-t_{j-1}\right)\right)$. . $z_{j-1}+h^{-1}\left(t-t_{j-1}\right) z_{j}$ for $t_{j-1} \leqq t \leqq t_{j}$. It follows from (5) and (7)

\section{Assertion 2.}

$$
\left.\left\|z^{n}(\tau)-z^{n}(\mu)\right\| \leqq|\tau-\mu| \underset{\langle 0, T\rangle}{\operatorname{Var} f}+\underset{\langle 0, T\rangle}{\operatorname{Max}}\|f(t)\|+\left\|A z_{0}\right\|\right) .
$$

Let us define $x^{n}(t)$ by $x^{n}(0)=u_{0}, x^{n}(t)=z_{j}$ for $(j-1) h<t \leqq j h$. In the same manner we define $f^{n}(t)$. It follows from the construction above that

$$
\left.\int_{0}^{t} A\left(x^{n}\right)(\tau)\right) \mathrm{d} \tau+z^{n}(t)=\int_{0}^{t} f^{n}(\tau) \mathrm{d} \tau+u_{0}
$$


and for the derivatives from the left:

$$
A\left(x^{n}(t)\right)+\frac{\mathrm{d}^{-} z^{n}}{\mathrm{~d} t}=f(t) .
$$

It follows from the definition of the functions $x^{n}(t)$ and $f^{n}(t)$ that for all $t \in\langle 0, T\rangle$, $f^{n}(t) \rightarrow f(t)$ (strong convergence), uniformly in $\langle 0, T\rangle$, and

$$
x^{n}(t)-z^{n}(t) \rightarrow 0 \quad \text { uniformly in }\langle 0, T\rangle .
$$

Assertion 3. $x^{n}(t) \rightarrow u(t)$ uniformly in $\langle 0, T\rangle$.

Proof. We have

$$
\begin{gathered}
\frac{\mathrm{d}^{-}}{\mathrm{d} t}\left\|z^{m}(t)-z^{n}(t)\right\|^{2}=2\left(\frac{\mathrm{d}^{-} z^{m}}{\mathrm{~d} t}(t)-\frac{\mathrm{d}^{-} z^{n}}{\mathrm{~d} t}(t),\right. \\
\left.z^{m}(t)-z^{n}(t)\right)=2\left(f^{m}(t)-A\left(x^{m}(t)\right)-f^{n}(t)+A\left(x^{n}(t)\right), z^{m}(t)-z^{n}(t)\right) .
\end{gathered}
$$

It follows from (8) and (10) that

$$
\left\|A\left(x^{n}(t)\right)\right\| \leqq \underset{\langle 0, T\rangle}{2 \operatorname{Max}}\|f(t)\|+\underset{\langle 0, T\rangle}{\operatorname{Var} f}+\left\|A z_{0}\right\|,
$$

hence (11), (12) and (13) give

$$
\begin{gathered}
\frac{\mathrm{d}^{-}}{\mathrm{d} t}\left\|z^{m}(t)-z^{n}(t)\right\|^{2} \leqq \varepsilon_{m, n}+2\left(f^{m}(t)-A\left(x^{m}(t)\right)-f^{n}(t)+\right. \\
\left.+A\left(x^{n}(t)\right), x^{m}(t)-x^{n}(t)\right) \leqq \varepsilon_{m, n}+2\left\|f^{m}(t)-f^{n}(t)\right\|\left\|x^{m}(t)-x^{n}(t)\right\|,
\end{gathered}
$$

where $\varepsilon_{m, n} \rightarrow 0$. Because $\left\|z^{m}(t)-z^{n}(t)\right\| \geqq 0$ and $\left\|z^{m}(0)-z^{n}(0)\right\|=0$, it follows that with some $\bar{\varepsilon}_{m, n} \rightarrow 0:\left\|z^{m}(t)-z^{n}(t)\right\| \leqq \bar{\varepsilon}_{m, n} t$, q.e.d.

We prove as in the paper [6] the following Assertions 4 and 5:

Assertion 4. $A$ is maximal monotone, i.e. if $(A v-w, v-u) \geqq 0$ for all $v$ in $D(A)$, then $u \in D(A)$ and $A u=w$.

Proof. We have $(A v-w+v-u, v-u) \geqq 0$. For fixed $z \in H, t>0$, put $v_{t}=A_{1}^{-1}(u+w+t z)$. It follows that $A v_{t}+v_{t}-u-w=t z$, hence $t\left(z, v_{t}-u\right) \geqq$ $\geqq 0$ so $\left(z, v_{t}-u\right) \geqq 0$. Letting $t \rightarrow 0+: v_{t} \rightarrow A_{1}^{-1}(u+w)$, hence $\left(z, A_{1}^{-1}(u+w)-\right.$ $-u) \geqq 0$ so $u=A_{1}^{-1}(u+w), u \in D(A)$, and $A u=w$, q.e.d.

Assertion 5. If $u_{j} \rightarrow u$ and $A u_{j} \rightarrow w$ (weak convergence) then $u \in D(A)$ and $A u=w$.

Proof. For $v \in D(A):\left(A v-A u_{j}, v-u_{j}\right) \geqq 0$. From this follows taking the limit as $j \rightarrow \infty$ that $(A v-w, v-u) \geqq 0$, hence by the Assertion 4, $u \in D(A)$ and $A u=w$, q.e.d. 


\section{Assertion 6.}

$$
\left.\|u(t)-u(\tau)\| \leqq|t-\tau| \underset{\langle 0, T\rangle}{\operatorname{Var} f}+\underset{\langle 0, T\rangle}{\operatorname{Max}}\|f(t)\|+\left\|A u_{0}\right\|\right) .
$$

Proof. (14) follows from (8), (11) and the Assertion 3.

Assertion 7. $A\left(x^{n}(t)\right) \rightarrow A(u(t))$ and $A(u(t))$ is weakly continuous.

Proof. We use estimations (13), (14) and Assertion 3 and 5.

Theorem. Let $A$ be a nonlinear operator from the domain $D(A) \subset H$ to $H$. Let (1) and (2) be satisfied. Let $u_{0} \in D(A), f(t)$ be continuous on $\langle 0, T\rangle$ with values in $H$ and of bounded variation on $\langle 0, T\rangle$. Then there exists a unique solution $u(t)$ of the initial problem (3) and $u(t)$ is a Lipschitz continuous function satisfying (14). For the functions $x^{n}, z^{n}$ constructed by the Rothe's method (8), (9), (10), (13) are valid. Also

$$
\begin{gathered}
z^{n}(t) \rightarrow u(t) \text { uniformly in }\langle 0, T\rangle, \\
A x^{n}(t) \rightarrow A(u(t)) .
\end{gathered}
$$

If $u, v$ are two solutions corresponding to the $f, u_{0}, g, v_{0}$ respectively, then

$$
\underset{\langle 0, T\rangle}{\operatorname{Max}}\|u(t)-v(t)\| \leqq 2 \int_{0}^{T}\|f(t)-g(t)\| \mathrm{d} t+\|u(0)-v(0)\| .
$$

If $f(t) \equiv 0$, then $\|A(u(t))\|$ is non-increasing.

Proof. First we prove (17) from which follows also uniqueness. We have

$$
\begin{gathered}
\frac{\mathrm{d}}{\mathrm{d} t}\|u(t)-v(t)\|^{2}=2(f(t)-g(t)-A(u(t))+A(v(t)), \\
u(t)-v(t)) \leqq 2\|f(t)-g(t)\|\|u(t)-v(t)\|,
\end{gathered}
$$

so

$$
\frac{\mathrm{d}}{\mathrm{d} t}\|u(t)-v(t)\|^{2} \leqq 2(\underset{\langle 0, T\rangle}{\operatorname{Max}}\|u(\tau)-v(\tau)\|)\|f(t)-g(t)\|,
$$

hence

$$
\|u(t)-v(t)\|^{2} \leqq\|u(0)-v(0)\|^{2}+2 \underset{\langle 0, T\rangle}{\operatorname{Max}}\|u(\tau)-v(\tau)\| \cdot \int_{0}^{T}\|f(\tau)-g(\tau)\| \mathrm{d} \tau,
$$

from which (17) follows. Let us consider first sequences $x^{n}(t), z^{n}(t)$ introduced above. 
It follows from (9) that for every $v \in H$

$$
\int_{0}^{t}\left(A\left(x^{n}(\tau)\right), v\right) \mathrm{d} \tau+\left(z^{n}(t), v\right)=\int_{0}^{t}\left(f^{n}(\tau), v\right) \mathrm{d} \tau+\left(u_{0}, v\right) .
$$

Hence from the Assertions 3,7 and from (11), it follows for $n \rightarrow \infty$ :

$$
\int_{0}^{t}(A(u(\tau)), v) \mathrm{d} \tau+(u(t), v)=\int_{0}^{t}(f(\tau), v) \mathrm{d} \tau+\left(u_{0}, v\right),
$$

hence it follows from (19) that $u(t)$ is weakly differentiable, because of the Assertions 7 , and that the equation (3) is satisfied. (15) and (16) are evident.

From (13) and the Assertion 7 we obtain for $f(t) \equiv 0$

$$
\|A(u(t))\| \leqq\left\|A u_{0}\right\|,
$$

hence from the uniqueness

$$
\|A(u(t))\| \leqq\|A(u(s))\|, \quad t \geqq s,
$$

q.e.d.

Remark. If $f(t) \equiv 0$, then clearly for two solutions corresponding to $u_{0}, v_{0}$ :

$$
\begin{gathered}
\frac{\mathrm{d}}{\mathrm{d} t}\|u(t)-v(t)\|^{2}=2\left(u^{\prime}(t)-v^{\prime}(t), u(t)-v(t)\right)= \\
=2(A(u(t))-A(v(t)), u(t)-v(t)) \leqq 0,
\end{gathered}
$$

hence the transition operator $U(t)$ defined by $U(t) u(0)=u(t)$ is nonexpansive.

\section{References}

[1] E. Rothe: Zweidimensionale parabolische Randwertaufgaben als Grenzfall eindimensionaler Randwertaufgaben. Math. Ann. 102 (1930), 650-670.

[2] O. A. Ладыжсенскал: Решение в целом первой краевой задачи для квазилинейных параболических уравнений ДАН СССР 107 (1956), 636-639.

[3] A. М. Илйин, А. С. Калашников, О. А. Олейник: Линейные уравнения второво порядка параболического типа, УНМ 17, vур. 3 (1962), 3-146.

[4] K. Rektorys: On application of direct variational methods to the solution of parabolic boundary value problems of arbitrary order in the space variables, Czech. Math. J. 21 (96) $1971,318-339$.

[5] J. Kačur: Method of Rothe and nonlinear parabolic boundary value problems of arbitrary order I, II, to appear in Czech. Math. J.,

[6] F. E. Browder: Existence theorems for nonlinear partial differential equations, Global Analysis, Proc. Symp. Pure Math. Vol. 16, Amer. Math. Soc. (1970) 1-60.

[7] H. Brézis: Opérateurs Maximaux Monotones, Mathematics Studies, North-Holland, 1973.

Author's address: 11567 Praha 1, Žitná 25, ČSSR (Matematický ústav ČSAV). 